\title{
STRATEGY DEVELOPMENT OF INFORMATION TECHNOLOGY-RELATED SERVICES USING TOWS MATRIX ANALYSIS: A CASE OF NEUST SAN ISIDRO CAMPUS
}

\author{
${ }^{1}$ EMMANUEL C. NAVARRO, MSIT, ${ }^{2}$ JENNILYN C. MINA, PhD, ${ }^{3}$ ROMEO B. \\ CAMPOS, JR., MBA
}

\begin{abstract}
${ }^{1}$ Training Coordinator, Nueva Ecija University of Science and Technology San Isidro Campus, San Isidro, Nueva Ecija 3106 Philippines

${ }^{2}$ On-the-Job Training Coordinator, Nueva Ecija University of Science and Technology San Isidro Campus, San Isidro, Nueva Ecija 3106 Philippines

${ }^{3}$ Guidance Coordinator, Nueva Ecija University of Science and Technology San Isidro Campus, San Isidro, Nueva Ecija 3106 Philippines

Correspondence: zedka_jen27@yahoo.com
\end{abstract}

\begin{abstract}
This study presents an in-depth analysis and strategic planning techniques for approaching a situation or achieving progress related to information technology services of Nueva Ecija University of Science and Technology, particularly the San Isidro Campus. As an educational organization and one in the region excellence providers in education, the University has so much vital information to manage and services to offer to provide the student's needs through the Management Information System department, application of IT services as a competing instrument to combat tedious tasks such as online admission, grade release, enrollment information, and online learning, university announcement, and possible students' internship.

The objective of this study is to determine the influence of information technology in day-to-day activities of the organization and strategy applied to streamline processes more conveniently.

The researchers develop a conceptual model that would analyze the IT services' impact by identifying its strengths, weaknesses, opportunities, and threats and cleverly act on it using the TOWS Matrix in generating strategic decisions. The overall results were beneficial to the University and MIS as a basis for formulating competitive strategies and integrating it in an extended development plan.
\end{abstract}

Keywords: IT related services, strategy development, SWOT, TOWS Matrix Analysis

\section{INTRODUCTION}

The logarithmic escalation of technology seems unstoppable. As information technology is changing rapidly (Benamati, Lederer, and Singh, 2016), cascading data of information technology scourging so much individual especially those who are not well-versed in the field of information technology - this is the common problem of now-a-days generation. Many seniors struggle with technology (The Conversation, 2020). Due to this scenario, anyone without tech skills is going to be left behind, whether socially or at work (Slabbert, 2016).

As a state university, the Nueva Ecija University of Science and Technology, which is considered as a home and nest of excellence in terms of academics and innovations is currently facing challenges due to the dramatic impact of the pandemic crisis that almost resembles into a new beginning of the entire humanity, the so-called "new-normal". 
The crisis brought confusions and inefficacies obscuring a great majority of humanity wherein the world has experienced a prolonged period of uncertainty and unrest (De Silva, 2020); however, great difficulties and trials entail the best idea to maintain the effervescence of life, economy, and all mass gathering such as schooling and the like.

Figuratively speaking - huge doors can be opened using small keys, likewise, brilliant minds must-see opportunities out of chaos. Facing, accepting, and going with the trend with an outstanding level of efficiency is the only model of success.

With its remarkable performance in the field of information technology, the university must withstand this new era of online learning, virtual classroom, and extending academic and nonacademic services thru electronic channels. The reality of the game, because of COVID-19, most professors and students suddenly find themselves forced to use technology as they teach and learn (Lederman, 2020). The wonders of modern technology allow students to enroll, make payments, receive, and submit school works online (Katigbak, 2018).

As the need arises, modifications of information technology and transformation of the university system and protocol into a more advanced technology embedded in different online platforms are now being measured. As the emergency subsides but normally fails to return, higher education institutions need to do more by engaging in varying stages of digital transformation (DeVaney, Shimshon, Rascoff, and Maggioncalda, 2020).

At this instant, the university administrators and IT experts must make strategic decisions. Strategic decisions determine the grand direction upon which an entity will embark (Rhodes, 2010). To find out what's working well and what's not so good in the university's IT-related services; a powerful but simple SWOT analysis technique is the solution (Mind Tools, 2020).

A SWOT can be used for any planning or analysis activity that could impact future finance, planning, and management decisions of the university to carry out a more comprehensive analysis. (Morrison, 2018). Amidst the pandemic crisis, the academic institutions across the country were buffeted with different trials that significantly reshape the procedures, systems, and protocols of different universities at large.

Determining the internal and external variables are simply the first step for determining strategic decision for it implies as a mere foundation of it. Thus, the researchers found it significant to make a SWOT analysis of the different information technology-related services of NEUST San Isidro Campus. Balancing and evaluating those variables will drive into a more effective decision making of the top management. Thus, the researchers on the other hand realized the need to use a TOWS Matrix Analysis which is a framework that is used to assess, create, compare, and finally decide upon the business strategies (Chowdhury, 2019). By the use of these tools in strategic management, the researchers would be able to come up with the best decisions that would be of great help to the management in this current situation.

\section{OBJECTIVES OF THE STUDY}

Successful institutions and fruitful endeavors are the output of effective planning and evaluation. Hence, the objective of this study is to determine the controllable and uncontrollable variables for Information Technology-Related Services of the campus as a basis for creating strategic actions and developments to enhance the abovementioned services of the institute. Furthermore, this study aimed to balance and utilize the available resources to uphold the current vision and mission of the organization thus, boosting the productivity level of the university personnel and reducing the operational cost without sacrificing the quality of the services. Lastly, the study is designed to analyze the Strengths, Weaknesses, Opportunities and Threats (SWOT) of the IT- 
Related Services of NEUST San Isidro Campus and to develop new strategies by combining the internal strengths with external opportunities and threats, and internal weaknesses with external opportunities and threats with the use of TOWS Matrix Analysis.

\section{METHODOLOGY}

This study used a SWOT analysis to identify the internal and external variables of the Information Technology-Related Services of NEUST San Isidro Campus. SWOT analysis is an important tool that serves as a support for decision-making and is often used as a tool for the systematic analysis of the organization, both internal and external influences on the organization (Yuksel and Dagdeviren, 2007). The researchers were able to determine the strengths, weaknesses, opportunities and threats of the services by interviewing the different stakeholders of the campus including the administrators, department chairs, faculty and staff, students and even IT experts who were able to experience the IT-related services of the said campus. Since SWOT is one of the most widespread methods of management and is an instrument used by managers in creating strategies (Kurttila, Pesonen, Kangas, and Kajanus, 2000), this is the best method to be used to develop new strategies that will further improve the said services of the campus. At the same time, this study developed alternative strategies based on those factors in the form of TOWS matrix which was developed by Weihrich (1982). TOWS matrix is the essential completing tool in this case study because it enhances positioning strategies considering the relations between Strengths, Weakness, Opportunities, and Threats as in SWOT analysis (Aslan, Çınar, and Kumpikaite, 2012). TOWS Analysis is an effective way of combining internal strengths with external opportunities and threats, and internal weaknesses with external opportunities and threats to develop a strategy (Ravanavar and Charantimath, 2012) because it forces the organization to really think about how they can improve themselves, how they can guard against threats and become more aware of their expertise and potential shortcomings (Mulder, 2017).

\section{RESULTS AND DISCUSSION}




\begin{tabular}{|c|c|c|}
\hline $\begin{array}{l}\text { NEUST SAN ISIDRO CAMPUS INFORMATION } \\
\text { TECHNOLOGY RELATED SERVICES }\end{array}$ & $\begin{array}{l}\text { S-STRENGTHS } \\
\text { 1. The institution is one hundred percent governed and } \\
\text { owned by the government } \\
\text { 2. Has an overseeing government institutions such as } \\
\text { CHED, COA, CSC and DBM } \\
\text { 3. Has the capacity to endorse application directly to } \\
\text { the office of the Civil Service Commission } \\
\text { 4. Well versed and trained faculty and staff in terms of } \\
\text { information technology } \\
\text { 5. The university assigned extension services for each } \\
\text { faculty member } \\
\text { 6. Has its own Management Information System } \\
\text { department } \\
\text { 7. Has the capacity to procure essential equipment for } \\
\text { upgrading system and online services }\end{array}$ & $\begin{array}{l}\text { W-WEAKNESSES } \\
\text { 1. Diverse campuses with dynamic culture } \\
\text { 2. Unstable internet connection due to demographic } \\
\text { location or site of some campuses } \\
\text { 3. Heavy online platforms or website that requires } \\
\text { highly reliable or strong internet connection } \\
\text { 4. Outdated computer specifications which cannot be } \\
\text { easily replaced due to strict implementation of } \\
\text { government condemnation guidelines } \\
\text { 5. Limited budget allotment } \\
\text { 6. Lack of system development team } \\
\text { 7. Vital information are vulnerable from hacker attack } \\
\text { due to unsecure computers }\end{array}$ \\
\hline $\begin{array}{l}\text { O-OPPORTUNITIES } \\
\text { 1. Capable of increasing employee productivity } \\
\text { 2. Can contribute to the society in minimizing the cost } \\
\text { of processing documents } \\
\text { 3. Able to assist the university to adapt flexible } \\
\text { learning } \\
\text { 4. Be able to minimize duplication of task } \\
\text { 5. Can decrease the paper consumption } \\
\text { 6. Will shorten the duration of each transaction } \\
\text { 7. Numerous number fresh IT graduates looking for } \\
\text { experience in their field }\end{array}$ & \begin{tabular}{|l|} 
SO STRATEGIES \\
1. Allocate bigger funds for information technology \\
projects $(\mathrm{S} 1, \mathrm{~S} 2, \mathrm{~S} 7, \mathrm{O} 6)$ \\
2. Strengthening/Intensifying the development team \\
which includes the recruitment of system developers \\
e.g. focus only to the system development, reduce \\
load for faculty, etc. ( $\mathrm{S} 4, \mathrm{~S} 6, \mathrm{O})$ \\
3. Develop school information system e.g. enrollment, \\
assessment, grading system ( $\mathrm{S} 5, \mathrm{~S} 6, \mathrm{O}, \mathrm{O}, \mathrm{O})$ \\
4. Partnering with project based developers ( $\mathrm{S} 6, \mathrm{O})$ \\
5. Hired newly graduate students of the university \\
skilled in programming ( $\mathrm{S} 6, \mathrm{O} 1, \mathrm{O})$
\end{tabular} & \begin{tabular}{|l} 
WO STRATEGIES \\
1. Re-structure of Management Information System \\
Department by hiring a resident and project based \\
system developers and by employing IT consultants \\
(W1, W5, W6, O1, O4, O6) \\
2. Tap faculty inclined in system development with \\
reduce teaching load (W5, W6, O1, O2, O3) \\
3. Subscription of Student Information System (W5, \\
O1, O5, O6) \\
4. Purchase network security system (W4,W5,W7, O4)
\end{tabular} \\
\hline $\begin{array}{l}\text { T-THREATS } \\
\text { 1. Cultural and technical adaptability of the } \\
\text { stakeholders } \\
\text { 2. Low level of students awareness regarding } \\
\text { electronic services } \\
\text { 3. Some government and private owned universities } \\
\text { inside and outside the province used automated } \\
\text { services } \\
\text { 4. Expensive but readily available computer system for } \\
\text { academic institution } \\
\text { 5. Too long guiding principle for procurement imposed } \\
\text { by the national government }\end{array}$ & $\begin{array}{l}\text { ST STRATEGIES } \\
\text { 1. Capability building by teaching the personnel new } \\
\text { skills particularly in Information Technology (S4, } \\
\mathrm{S} 5, \mathrm{~S} 6, \mathrm{~T} 1, \mathrm{~T} 2) \\
\text { 2. Develop a modular phased enrolment system ( } \mathrm{S} 6, \mathrm{~S} 7, \\
\mathrm{~T} 3, \mathrm{~T} 4, \mathrm{~T} 5) \\
\text { 3. Consider outsourced software development }(\mathrm{S} 6, \mathrm{~T} 4 \text {, } \\
\mathrm{T} 6)\end{array}$ & \begin{tabular}{|l} 
WT STRATEGIES \\
1. Procurement of IT devices, system development \\
(W4, W5, T4, T5) \\
2. End-users training for developed system \\
(students/staff-primary users) (W1, T1, T2) \\
3. Additional manpower to handle Information \\
Technology related services (W5, W6, T1, T3) \\
4. Acquire IT equipment for both hardware and \\
software (W5, T4, T5) \\
5. Additional subscription for high speed internet \\
connectivity that will cater the needs of the whole \\
campus (W2, W3, W4, W5, T3, T4, T5)
\end{tabular} \\
\hline
\end{tabular}

Figure 1. TOWS Matrix of Information Technology-Related Services

\section{SO STRATEGIES} of NEUST San Isidro Campus

1. Allocate bigger funds for information technology projects (S1, S2, S7, O6)

The reality of a changing world manifest in a day-to-day scenario, things that are applicable today, might not be longer applicable in the future. Technology is changing the world at an astonishing pace (Scharre, 2017). Rapid changes require rapid movement, thus as an independent institution with sovereignty over the resources entrusted by the national government, NEUST as a center of excellence in the field of technology must appropriate equitable funds for Information Technology projects to ensure the effervesce of system development.

As learning becomes increasingly virtual, web-based, and wireless, it still must physically take place somewhere. As information technology is becoming ubiquitous, the university should intensify the Income Generating Projects to escalate the cash inflow that can be a great source of fund to support IT-related projects since the maintenance and modernization needs of schools require both one-time and continuing sources of money, with maintenance and modernization requiring different approaches (Lackney, 2000).

2. Strengthening/Intensifying the development team which includes the recruitment of system developers e.g. focus only to the system development and reduce load for faculty, etc. (S4, S6, O1)

Motivation, whether intrinsic or extrinsic pays a lot to the productivity level of the stakeholders involved in the development process, also, employee empowerment by recruiting individuals who are highly specialized in that field of knowledge can boost the quality of output due to collaborative effort and synergy. Research has regularly 
demonstrated that when employees feel empowered at work, it is associated with stronger job performance, job satisfaction, and commitment to the organization (Lee, Willis, and Tian, 2018).

Hence, the top management must ensure that the responsibilities and authorities for relevant roles are assigned, communicated, and understood (Biswas, 2018) within the organization. to avoid overstaffing, job repetition, and over-lapping of duties and responsibilities within the unit or department, thus promoting a higher level of efficiency.

3. Develop school information system e.g. enrollment, assessment, grading system (S5, S6, 04, 06)

A centralized source of information coming from the Management Information System will cascade a strong standard in academic and non-academic practices within the university. When all the data is centralized, processed, cleansed, analyzed, and stored in one place, the staff will spend less time organizing the data and more time focusing on achieving the university's goals (Smallcombe, 2019). This system shall manage to ease the task of administration, teachers, staff, and others through a multi-function platform (Fadiyah, 2019).

Providing a grading system, grade evaluation and student assessment for a common program will promote cohesion in the assessment of learning regardless of campus. Thus, students from the main campus can tap satellite campuses nearby to their area for enrollment and other students' services, and vice versa.

In connection to this, the administration must delegate the task or responsibility to the department because effective managers know what responsibilities to delegate (Lloyd, 2020) with a common or shared curriculum to avoid misevaluation of grades so that the students with regular status can take advantage of these amazing opportunities that can give them more benefits.

\section{WO STRATEGIES}

1. Re-structure of Management Information System Department by hiring a resident and project based system developers and by employing IT consultants (W1, W5, W6, 01, 04, 06)

Hiring a resident for system development from internal non-academic IT employees, IT professors, and key personnel is a huge advantage. The team is always available and surely understands the university and its culture (Waszkowski, 2017). Thus, it will give a more vivid overview of the entire university system since they are more familiar with the protocols of the university aligned to its objectives and standards.

As the saying goes, too many cooks in the kitchen will jeopardize the taste and quality of the food, therefore, screening the members of the team is quite crucial, especially if the system is for academic purposes and protocols; the team must tap or seek help from academician to enlighten the path, however, if the concern is non-academic, e.g. Registrar's Office, the team must seek for the guidance of a certain employee affiliated to that department to provide an exact road map of the department's protocol.

2. Tap faculty inclined in system development with reduce teaching load (W5, W6, O1, O2, 03)

One of the busiest departments in a highly established automated institution is the Management Information System office. It is an organizational method of providing past, present, and projected information related to internal operations and external aptitude 
(Asemi, Safari, and Zavareh, 2011). This department supports the planning, control, and operation functions of an organization by furnishing uniform information in the proper time frame to assist the decision makers (Waston, 1987).

That is why the MIS department is considered as the heart of an organization's operation; once its day-to-day operation stopped, it may paralyze their service and bring massive injury to the company. The MIS department alone cannot deliver smooth and achieve a high-efficiency level, especially maintaining a mammoth university with satellite campuses. Thus, it needs the teaching staff's services that have worked in the IT industry and are technically inclined and experienced in system development. Developers will be a great addition in assisting the MIS to increase its operational productivity. In service return, a deduction of its institutional function which involves instruction, hence focusing on research and extension services through system development.

\section{Subscription of Student Information System (W5, 01, 05, O6)}

Students are required to opt-into information sheets for the university to navigate the academic performance and non-academic activities of the student for proper assessment and tracing; it automates individual tasks that are repetitive and time-consuming (Deshpande, 2019). The Student Information System will serve as a pool of data that is accessible to all employees bound to the laws and restrictions of the Data Privacy Act. Assessable yet it requires permission. The university must make decisions that are made according to the established management guidelines (Asemi, Safari, and Zavareh, 2011), especially if it is to the extent of information and data that are available to the general public and stakeholders. If the data needed is restricted, the user/stakeholder must seek approval of the person or the person in authority to grant permission.

4. Purchase network security system (W4, W5, W7, O4)

Security is a strong foundation for the success of an organization. The need for information security has risen to high levels for both personal and institutional use (Yildirima, Akalpa, Aytac, and Bayramb, 2010). Nowadays, huge companies with physical and IT assets invest in protecting those assets. There are various ways to secure corporate assets and it can be by imposing strict guidelines and use of technologies in safeguarding the data. It can be steered by mere application of ID badges for each employee, passwords for all software programs, use of magnetic cards, biometric readers, and scanners. Those above-mentioned security features are the standard but not resilient enough to counter-attack those people who wanted to harm or damage the institution deliberately.

Outside attacks are mostly performed by hackers who have devised numerous ways to steal important data (Johar, 2017). They would maliciously infiltrate the system to steal data, and in return, they would ask for a certain amount of money in exchange for the stolen data.

As the university continues to progress in developing and investing computer systems, there is a dire need to purchase a network security system to ensure that all developed systems and data are kept secured. Also, this complies with the Republic Act 10173-Data Privacy of Act of 2012, wherein the organization is bound to safeguard its stakeholder's individual information (National Privacy Commission, 2012).

\section{ST STRATEGIES}


1. Capability building by teaching the personnel new skills particularly in Information Technology (S4, S5, S6, T1, T2)

A sophisticated program requires new blood of knowledge, thus the university must conduct an intense and precise program for faculty development focusing exactly in this field of Information Technology because a large knowledge base exists on effective training and faculty development practices in general (Kitano, Dodge, Harrison, and Lewis, 1998).

Formulation of web-based online platform that is accessible in all types of operating system is also a dais that does not require high specification of electronic devices. Webbased training platforms provide a range of tools for transmitting and acquiring new knowledge, skills, and attitudes which aims to encourage and guide the learning process through the use of computer and Internet connection (Tosheva, 2016).

2. Develop a modular phased enrolment system (S6, S7, T3, T4, T5)

In conceptualizing a new system, many things need to be prioritized; a process to follow, a specific requirement to address, and a system architecture model. The life cycle process in developing a system includes development stages from planning, analysis, development, integration and testing, implementation, operation, and maintenance.

Developing a system by phased will give cynosure to the details of functionality. Involving several people to work cooperatively may result in the speedy development of the system. Aside from that, the developer will hold additional time to test system performance and focus only on the assigned modules. In this manner, accomplishing results will be more significant in effective and efficient system development.

3. Consider outsourced software development (S6, T4, T6)

The output of collaborative effort and solidarity is more cohesive for it can really fuel-up the productivity and quality of outputs. Overseeing parties can also contribute to their experience and wisdom obtained in the practice of the same field.

The university resources are very limited, though funded by the national government, procurement requires a thorough application of guidelines mandated by external government agencies to promote full transparency and liquidity, thus, moreover finding an additional source of income in the form of IGP or fund realignment is one of the strategic methodologies for this endeavor to materialize.

\section{WT STRATEGIES}

1. Procurement of IT devices, system development (W4, W5, T4, T5)

Advanced computer program requires advance specification of computer servers to avoid delay and system downfall due to massive users that simultaneously using the software or online-based website.

The world is ever-changing, thus preparation of the Annual Procurement Plan must be prepared with higher frequency per annum to anticipate the changes and unforeseen needs of the institution specified in the field of Information Technology.

2. End-users training for the developed system (students/staff-primary users) (W1, T1, T2)

The fruit of success of efficiency and effectiveness of the developed system relies on the end-users' participation. It plays an essential factor in shaping the downfall and progress of the system. The Administration must conduct thorough training operation staff before the deployment of the system. During training, a manual or a user guide must provide. In 
doing this process, it can eliminate disturbance of the operation and increase productivity as well. As the university's primary customer, the students, must also undergo training on utilizing the system that our university can offer to serve them better.

3. Additional manpower to handle Information Technology related services (W5, W6, T1, T3)

A specific individual doing a certain thing on a daily basis will provide mastery and a high level of a learning curve because of the margin obtain in a day-to-day experiences.

The university must designate specialized personnel for monitoring the function of the system. The personnel must be equipped enough in handling computer errors in terms of hardware and software. Also, the university must provide a prescribed facility to cater to the requirement in terms of electronics and climate control to maintain the operation of the central system.

4. Acquire IT equipment for both hardware and software (W5, T4, T5)

Technology, at its best, requires state of the art facilities and equipment. Acquisition of IT infrastructure will boost productivity in developing, project monitoring and managing, and supporting IT services. In the most recent Society for Information Management (SIM) Delphi study (Brancheau, Janz, and Wetherbe, 1996), senior IT executives responded that the building and development of a flexible and responsive IT infrastructure was the most important issue of IT management.

Getting it right needs everyone to get on board and pledge commitment to formulate strategic planning that is why IT educators should check and observe the trends in the world of IT to keep updated (Mina, Reyes and Garcia, 2020). These cannot be done alone by the Management Information System department because it needs support from the top management down to the operation level. A massive benchmarking is also a thing to consider to come up with the best relevant results.

5. Additional subscription for high speed internet connectivity that will cater the needs of the whole campus (W2, W3, W4, W5, T3, T4, T5)

Reliable internet providers for stable online connection - this is only possible if the service provider is really capable to provide a stable internet connection, such, intensifying the speed internet connectivity will stabilize the internet connection of the campus despite the massive number of users.

Additional speed means additional cost. The trade-off of quality and cost is a major play in this type of strategy, thus finding other sources of income from IGP's or NGO's is a vital attribute of this concept. More so, finding cheaper internet providers, yet more reliable is one way to obtain this plan.

\section{CONCLUSION AND RECOMMENDATION}

The study is advantageous to the University, especially to the Management Information System as the oversight department in promulgating and implementing IT services. To provide quality service, the organization must always be one-step ahead and should remain competitive. Based on the gathered SWOT, the organization is governed, owned, and run by the state and is accredited by some governmental institutions such as CHED, COA, CSC, and DBM and has partnered with a group of agencies in ensuring that the quality of service was delivered.

The organization has computer technology resources, network infrastructure, computer systems, internet connectivity limited to places with network connections, and MIS offices that manned program developers. However, despite having that, it is insufficient to render service seamlessly. 
Not all computer technology is a state of the art; some are way behind with the latest specifications. The network infrastructure is vulnerable; computer systems are not fully automated and have a small developer team group.

In doing this, supports coming from the top executives would play a vital role in computer technology operation. The University must gather the key departments involved in the process to join the strategic planning in improving work productivity and ensuring that the team is on the right track. The use of SWOT analysis was suggested in dissecting each circumstance that significantly affects the organization. After careful planning, the use of the TOWS matrix is incorporated as a basic tool for strategic analysis. The results of SWOT analysis shows an essential part in formulating comprehensive decisions by linking external and internal factors to help the organization to come out with strategic options. The organization must allocate more significant funds in technology development to supply the stakeholders' demands and needs. Tap the support of the faculty who have software development experience. Hire project-based developers and consider subscribing to the computer company that offers a school information system to give way for the development team to build an in-house school information system. And lastly, the researchers suggest that a follow-up study that will show a detailed long-term IT infrastructure development plan shall be conducted.

\section{REFERENCES}

1. Benamati, J.S., Lederer, A. and Singh, M. (2016). Information Technology Change: The Impact on it Management. Journal of Computer Information Systems, Volume 38, Issue 4

2. The Conversation (2020). Seniors struggle with technology, and often their kids won't help. Retrieved on August 31, 2020 from: https://theconversation.com/seniors-strugglewith-technology-and-often-their-kids-wont-help-130464

3. Slabbert, Blayne (2016). Most people struggle with tech. Retrieved on August 31, 2020 from: $\quad$ https://www.stuff.co.nz/technology/digital-living/87475073/most-peoplestruggle-with-tech

4. De Silva, Raymund (2020). COVID-19: Its Impact on the Philippines - Parts I, II, III and IV of V. Retrieved on September 01, 2020 from: http://www.europesolidaire.org/spip.php?article52772

5. Lederman, Doug (2020). Will Shift to Remote Teaching Be Boon or Bane for Online Learning? Retrieved on September 01, 2020 from: https://www.insidehighered.com/digital-learning/article/2020/03/18/most-teaching_ going-remote-will-help-or-hurt-online-learning

6. Katigbak, Karr (2018). Schools Offering Online Courses In The Philippines. Retrieved on September 01, 2020 from: https://portal.edukasyon.ph/blog/schools-offering-onlinecourses-in-the-philippines

7. DeVaney, J., Shimshon, G., Rascoff, M., and Maggioncalda, J. (2020). Higher Ed Needs a Long-Term Plan for Virtual Learning. Retrieved on September 01, 2020 from: https://hbr.org/2020/05/higher-ed-needs-a-long-term-plan-for-virtual-learning

8. Rhodes, Mark (2010). What is a Strategic Decision? Retrieved on September 01, 2020 from: $\quad$ https://managementhelp.org/blogs/strategic-planning/2010/10/12/what-is-astrategic-decision/

9. Mind Tools (2020). SWOT Analysis: How to Develop a Strategy For Success. Retrieved on September 02, 2020 from: https://www.mindtools.com/pages/article/newTMC_05.htm 
10. Morrison, Mike (2018). SWOT Analysis for Education, Schools, Colleges and Universities. Retrieved on September 01, 2020 from: https://rapidbi.com/swot-analysisfor-schools-and-education/

11. Chowdhury, Oindrila (2019). What is the TOWS Matrix? And how it is used? Retrieved on September 01, 2020 from: https://tradebrains.in/tows-matrix/

12. Yuksel, I., Dagdeviren, M. (2007). Using the analytic network process (ANP) in a SWOT analysis-A case study for a textile firm, Information Sciences 177:3364-3382

13. Kurttila, M., Pesonen, M., Kangas, M., Kajanus, M. (2000). Utilizing the analytic hierarchy process AHP in SWOT analysis a hybrid method and its application to a forestcertification case, Forest Policy and Economics 1: 41-52

14. Weihrich, H. (1982) The TOWS matrix-A tool for situational analysis, Long Range Planning, Vol. 15, No. 2, 54-66

15. Aslan, I., Çınar, O. and Kumpikaite, V. (2012). Creating Strategies from TOWS Matrix for Strategic Sustainable Development of Kipaş Group. Journal of Business Economics and Management, ISSN 1611-1699 print/ISSN 2029-4433 online, Volume 13(1): 95110 doi:10.3846/16111699.2011.620134

16. Ravanavar, G. and Charantimath, P. (2012). Strategic Formulation Using Tows Matrix-A Case Study. International Journal of Research and Development, Vol. 1 No.1

17. Mulder, Patty (2017). TOWS Matrix. Retrieved on September 05, 2020 from: https://www.toolshero.com/strategy/tows-matrix/

18. Scharre, Paul (2017). Retrieved on September 06, 2020 from: https://www.cnas.org/publications/commentary/making-sense-of-rapid-technologicalchange

19. Lackney, Jeffrey A. (2000). Thirty-Three Educational Design Principles for Schools and Community Learning Centers. Washington, DC: National Clearinghouse for Educational Facilities. Retrieved on September 06, 2020 from: https://education.stateuniversity.com/pages/2394/School-Facilities.html

20. Lee, A., Willis, S., and Tian, W. (2018). When Empowering Employees Works, and When It Doesn't. Retrieved on September 06, 2020 from: https://hbr.org/2018/03/whenempowering-employees-works-and-when-it-doesnt

21. Biswas, Pretesh (2018). IATF 16949:2016 Organizational roles, responsibilities, and authorities. Retrieved on September 06, 2020 from: http://isoconsultantpune.com/iatf169492016-organizational-roles-responsibilities-and-authorities/

22. Smallcombe, Mark (2018). Top 5 Reasons to Centralize Data \& Become a Data-Driven Business. Retrieved on September 06, 2020 from: https://www.xplenty.com/blog/top-5reasons-to-centralize-data/

23. Fadiyah, Syifa (2019). 10 Reasons Why School Management System is Important. Retrieved on September 13, 2020 from: https://www.hashmicro.com/blog/theimportance-of-school-management-system/

24. Lloyd, Sam (2020). Managers Must Delegate Effectively to Develop Employees. Retrieved on September 14, 2020 from: https://www.shrm.org/resourcesandtools/hrtopics/organizational-and-employee-development/pages/delegateeffectively.aspx

25. Waszkowski, Emil (2017). Pros and Cons of In-House and Outsourcing Software Development (Updated). Retrieved on September 14, 2020 from: futuremind.com/blog/pros-and-cons-of-outsourcing-software-development 
26. Asemi, A., Safari, A., and Zavareh, A. (2011). The Role of Management Information System (MIS) and Decision Support System (DSS) for Manager's Decision Making Process. International Journal of Business and Management, ISSN 1833-3850 E-ISSN 1833-8119, Vol. 6, No. 7 doi:10.5539/ijbm.v6n7p164

27. Waston, H.J., Carroll, A. B., \& Mann, R. I. (1987). Information Systems for Management. Plano, TX: Business Publications Inc.

28. Deshpande, Ashish (2019). How Emerging Technologies Are Changing the Future of Work. Retrieved on September 15, 2020 from: https://readwrite.com/2019/06/13/howemerging-technologies-are-changing-the-future-of-work/

29. Yildirima, E., Akalpa, G., Aytac, S., and Bayramb, N. (2010). Factors influencing information security management in small-and medium-sized enterprises: A case study from Turkey. International Journal of Information Management, pp. 360-365 doi:10.1016/j.ijinfomgt

30. National Privacy Commission (2012). Republic Act 10173 - Data Privacy Act of 2012. Retrieved on September 14, 2020 from: https://www.privacy.gov.ph/data-privacy-act/

31. Johar, Ankush (2017). Internet security 101: Six ways hackers can attack you and how to stay safe. Retrieved on September 14, 2020 from: https://economictimes.indiatimes.com/tech/internet/internet-security-101-six-wayshackers-can-attack-you-and-how-to-stay-safe/articleshow/61342742.cms?from=mdr

32. Kitano, Margie K., Dodge, Bernard J., Harrison, Patrick J., and Lewis, Rena B., (1998). Faculty Development in Technology Applications to University Instruction: An Evaluation. To Improve the Academy, University of Nebraska-Lincoln https://digitalcommons.unl.edu/podimproveacad/408

33. Tosheva, Emilia (2016). Web Based E-Learning Platforms. Retrieved on September 14, 2020 from: https://www.researchgate.net/publication/316716574_WEB_BASED_ELEARNING_PLATFORMS

34. Brancheau, J.C., Janz, B.D., and Wetherbe, J.C. (1996) Key issues in information systems management: 1994-95 SIM Delphi results. MIS Quarterly, 20, 2, pp. 225-242

35. Mina, J., Reyes, E.J. and Garcia, M. (2020). Industry Partners' feedback on the OJT performance of Bachelor of Science in Information Technology (BSIT) Students. International Journal of Advanced Engineering, Management and Science (IJAEMS), ISSN: 2454-1311 Vol-6, Issue-4, Apr-2020 https://dx.doi.org/10.22161/ijaems.64.3 